\title{
Incidence and Risk Factors for Bone Metastasis in Non-Small Cell Lung Cancer
}

\author{
Gustavo Telles da Silva, Anke Bergmann, Luiz Claudio Santos Thuler*
}

\begin{abstract}
Background: Bone is a frequent site of metastasis from various primary cancers including with Non-Small Cell Lung Cancer. The aim of this study was to investigate the incidence and risk factors for Bone Metastasis in patients with Non-Small Cell Lung Cancer. Methodology: A cohort study was carried out in patients diagnosed with Non-Small Cell Lung Cancer between 2006 and 2014 in a single cancer centre. A descriptive analysis of the population was compiled based on mean \pm standard deviation (SD) for continuous variables and percentage (\%) for categorical variables. Univariate and multivariate Cox proportional hazards regression analyses were carried out to quantify the relationship between independent variables and the outcome variable (Bone Metastasis). Results: During the study period 1025 patients were diagnosed with Non-Small Cell Lung Cancer. Bone Metastasis was detected in 136 patients (13.2\%) with a mean interval between Non-Small Cell Lung Cancer diagnosis and Bone Metastasis of 8.07 months (95\% CI: 7.68 8.45). Multivariate analysis revealed that younger age (HR 0.97; 95\%CI, 0.95-0.99; $\mathrm{p}=0.002$ ), adenocarcinoma (HR 1.51; 95\%CI, 1.06-2.15; $\mathrm{p}=0.021$ ) and treatment with chemotherapy, radiotherapy or chemotherapy combined with radiotherapy (HR 3.73; 95\%CI, 2.30-6.05; $<<0.001$ ) were associated with the occurrence of Bone Metastasis. Conclusion: The incidence of Bone Metastasis was 13.2\%. Younger age, histological subtype adenocarcinoma and treatment with chemotherapy, radiotherapy or chemotherapy combined with radiotherapy are independent risk factors for Bone Metastasis.
\end{abstract}

Keywords: Bone metastasis- non-small cell lung cancer- risk factors- incidence

Asian Pac J Cancer Prev, 20 (1), 45-51

\section{Introduction}

Worldwide, lung cancer (LC) is the most frequently diagnosed cancer in men and remains the leading cause of cancer-related deaths in developed countries and less developed countries (Torre et al., 2015). There were an estimated 18,740 new cases in men and 12,530 new cases in women in 2018-19; these figures represent crude incidence rates of 18.16 and 11.81 per 100,000 , respectively (Brasil, 2018).

Non-small cell lung cancer (NSCLC) is the predominant form of $\mathrm{LC}$ and accounts for $80 \%$ of all LC cases (Sathiakumar et al., 2013). LC is normally diagnosed when the disease has already progressed locally or systematically, because the early stages of the disease are often without symptoms (Sathiakumar et al., 2013; Hirsh, 2009; Roodman, 2004). Bone is a frequent site of metastasis from various primary cancers including NSCLC, and 30 to $40 \%$ of NSCLC patients develop bone metastasis (BM) during the course of the disease (Kuchuk et al., 2015; Hirsh, 2009; Tsuya et al., 2007; Coleman, 2006).

$\mathrm{BM}$ are associated with disruption of normal bone turnover which leads to pain and debilitating complications known as skeletal-related events. These include pathological fracture, spinal cord or nerve root compression, requirement of surgery, radiotherapy to bone, or hypercalcemia of malignancy (Ezat et al., 2016; Phanphaisarn et al., 2016; Coleman, 2006). These events have a negative impact on quality of life and functioning and increase use of healthcare resources (Da Silva et al., 2016; Duran et al., 2016; Pereira et al., 2016; Lipton et al., 2016; Oster et al., 2015; Hoefeler et al., 2014). In recent years there has been an increase in the number of publications analysing BM patients with NSCLC; however few studies have assessed the risk factors for BM in patients with NSCLC (Ulas et al., 2016; Sathiakumar et al., 2013; Bae et al., 2012; Tsuya et al., 2007). Accurate estimates of the number of patients at risk for BM are essential to improving our understanding of the burden of this complication in NSCLC patients and allocation of healthcare resources. The purpose of this study was, therefore, to investigate the incidence and the risk factors for BM in patients with NSCLC. 


\section{Materials and Methods}

\section{Methodology}

A cohort study was carried out in patients diagnosed with NSCLC between 2006 and 2014, who were treated exclusively at the Brazilian National Cancer Institute (INCA). In total 1112 patients with pathological confirmation of NSCLC were identified. The histological subtypes included in this study, according to the International Classification of Diseases for Oncology 3 nd Edition (ICD-O-3) were: squamous cell carcinoma (codes 8050-8076), adenocarcinoma (8140-8211, 8230-8231, $8250-8260,8323,8480-8490,8550-8560,8570-8572$ ) and large cell carcinoma $(8012-8031,8310)$. To accurately quantify the association with risk factors, we excluded patients with confirmed BM at diagnosis of NSCLC $(\mathrm{n}=87)$.

Clinical and socio-demographic data were extracted from physical and electronic medical records. The variables investigated were: gender, age, ethnicity, marital status, years of education $(\leq 8 ;>8)$, history of smoking (categorized as never smokers versus smokers/ former smokers), alcohol consumption ( $>3$ times per week, independent of the amount consumed), histology, staging, body mass index (BMI), Eastern Cooperative Oncology Group Performance Status (ECOG-PS), history of use of epidermal growth factor receptortyrosine kinase inhibitors (EGFR-TKI) and treatment for NSCLC. Five treatment groups were analysed: (1) surgery; (2) chemotherapy; (3) radiotherapy (RT); (4) surgery combined with chemotherapy (SC); and (5) chemotherapy combined with radiotherapy (CRT).

$\mathrm{BM}$ was the time-dependent outcome of main interest. Diagnoses of BM were confirmed using one the following methods: standard radiography, bone scintigraphy, computerised tomography (CT) or magnetic resonance imaging (MRI). All patients were followed from diagnosis of NSCLC until the occurrence of BM, death, date of last contact (in the case of patients lost to follow-up) or the end of the study period (i.e., April 31, 2016).

A descriptive analysis of the population was compiled using mean \pm standard deviations (SD) for continuous variables and percentage (\%) for categorical variables. Univariate and multivariate Cox proportional hazards regression analyses were carried out to quantify the relationship between independent variables and the outcome variable (BM). A Cox multiple regression model was calculated using the forward stepwise method. Variables with a p-value $<0.20$ in univariate analysis and clinically significant variables were selected for multiple regression modelling. Only variables with $\mathrm{p}<0.05$ were retained in the final model. All statistical tests were twotailed. Analyses were performed with SPSS (Statistical Package for the Social Sciences for Windows, São Paulo, Brazil) version 21.0.

This research was approved by the research ethics committee of the INCA (protocol CAAE: 11556513.2.0000.5274, number 233 245/2013).

\section{Results}

One thousand and twenty-five patients were diagnosed with NSCLC between January 2006 and December 2014. Their mean age at diagnosis was 63.4 years $(\mathrm{SD}=9.5)$. Table 1 presents socio-demographic data for the study cohort. The majority of patients were male $(62.0 \%)$, white $(66.5 \%)$, married $(59.6 \%)$, had a low level of education $(50.8 \%)$ and a history of smoking $(86.6 \%)$. Almost half the patients $(46.9 \%)$ were classified as eutrophic and $73.1 \%$ had good PS (PS $0=14.9 \%$; PS $1=58.2 \%$ ). Fifty-six percent were in advanced stages of the disease at diagnosis (Stage IIIb $=27.4 \%$; Stage IV $=28.7 \%$ ). The distribution of histological subtypes was adenocarcinoma in $51.4 \%$, squamous cell carcinoma in $46.0 \%$ and large cell carcinoma in $2.6 \%$. The majority of patients were treated with CRT $(27.2 \%)$ and only 34 patients $(3.3 \%)$ were treated with EGFR-TKI (Table 2).

$\mathrm{BM}$ was detected in 136 patients $(13.2 \%)$ during follow-up. The mean interval between NSCLC diagnosis

Table 1. Socio-Demographic Characteristics $(n=1025)$

\begin{tabular}{|c|c|}
\hline Characteristics & $\mathrm{n}(\%)$ \\
\hline \multicolumn{2}{|l|}{ Gender } \\
\hline Male & $636(62.0)$ \\
\hline Female & $389(38.0)$ \\
\hline \multicolumn{2}{|l|}{ Age at diagnosis } \\
\hline $27-50$ & $88(8.6)$ \\
\hline $51-60$ & $316(30.8)$ \\
\hline $61-70$ & $372(36.3)$ \\
\hline $71-89$ & $249(24.3)$ \\
\hline \multicolumn{2}{|l|}{ Ethnicity } \\
\hline White & $682(66.5)$ \\
\hline Mulatto & $237(23.1)$ \\
\hline Black & $91(8.9)$ \\
\hline Missing & $15(1.5)$ \\
\hline \multicolumn{2}{|l|}{ Marital Status } \\
\hline Married & $611(59.6)$ \\
\hline Single & $145(14.2)$ \\
\hline Widowed & $133(13.0)$ \\
\hline Divorced & $109(10.6)$ \\
\hline Missing & $27(2.6)$ \\
\hline \multicolumn{2}{|l|}{ Years of Education } \\
\hline$\leq 8$ years of study & $521(50.8)$ \\
\hline$>8$ years of study & $475(46.4)$ \\
\hline Missing & $29(2.8)$ \\
\hline \multicolumn{2}{|l|}{ Smoking } \\
\hline Smokers/former smokers & $887(86.6)$ \\
\hline Never smokers & $109(10.6)$ \\
\hline Missing & $29(2.8)$ \\
\hline \multicolumn{2}{|l|}{ Alcohol consumption } \\
\hline Yes & $551(53.8)$ \\
\hline No & $349(34.0)$ \\
\hline Missing & $125(12.2)$ \\
\hline
\end{tabular}


Table 2. Clinical Characteristics $(n=1025)$

\begin{tabular}{|c|c|}
\hline Characteristics & $\mathrm{n}(\%)$ \\
\hline \multicolumn{2}{|l|}{ Body Mass Index } \\
\hline Underweight & $119(11.6)$ \\
\hline Eutrophic & $480(46.9)$ \\
\hline Overweight / Obese & $261(25.4)$ \\
\hline Missing & $165(16.1)$ \\
\hline \multicolumn{2}{|l|}{ Performance Status } \\
\hline 0 & $153(14.9)$ \\
\hline 1 & $597(58.2)$ \\
\hline 2 & $199(19.4)$ \\
\hline 3 & $59(5.8)$ \\
\hline 4 & $1(0.1)$ \\
\hline Missing & $16(1.6)$ \\
\hline \multicolumn{2}{|l|}{ Staging } \\
\hline I & $126(12.3)$ \\
\hline II & $87(8.5)$ \\
\hline IIIa & $172(16.8)$ \\
\hline IIIb & $281(27.4)$ \\
\hline IV & $294(28.7)$ \\
\hline Missing & $65(6.3)$ \\
\hline \multicolumn{2}{|l|}{ Histology } \\
\hline Adenocarcinoma & $526(51.4)$ \\
\hline Squamous Cell Carcinoma & $472(46.0)$ \\
\hline Large Cell Carcinoma & $27(2.6)$ \\
\hline \multicolumn{2}{|l|}{ History of EGFR-TKI therapy } \\
\hline Yes & $34(3.3)$ \\
\hline No & $991(96.7)$ \\
\hline \multicolumn{2}{|l|}{ NSCLC Treatment } \\
\hline CRT & $279(27.2)$ \\
\hline Chemotherapy & $262(25.6)$ \\
\hline Radiotherapy & $249(24.3)$ \\
\hline $\mathrm{SC}$ & $112(10.9)$ \\
\hline Surgery & $123(12.0)$ \\
\hline
\end{tabular}

EGFR-TKI, Epidermal Growth Factor Receptor-tyrosine Kinase Inhibitor; NSCLC, Non-Small-Cell Lung Cancer; SC, Surgery combined with chemotherapy; CRT, Chemotherapy combined with radiotherapy.

and development of BM was 8.1 months (95\% CI: 7.7 8.5) (Figure 1). The mean interval between diagnosis of NSCLC and development of BM was 9.6 months $(95 \%$ CI: 9.110 .0$)$ for patients diagnosed at stage I, 8.4 months (95\% CI: 7.5 9.3) for patients diagnosed at stage II, 6.8 months at stage III (95\% CI: 6.1 7.6) and 5.7 months $(95 \%$ CI: 4.9 6.6) for patients at stage IV. This difference was statistically significant $(p<0.001)$ (Figure 2$)$. In $27.2 \%$ of cases BM were located in spinal column with vertebral involvement, in $14.7 \%$ in the pelvis, in $14.0 \%$ in ribs, in $3.0 \%$ in the femur and in $3.0 \%$ in the humerus. Other less frequent sites were skull, scapula, clavicle, radius and hand. Single BM were more common than multiple (60.3\% versus $39.7 \%$, respectively).

Univariate analysis of demographic and clinical variables with occurrence of BM as the dependent variable

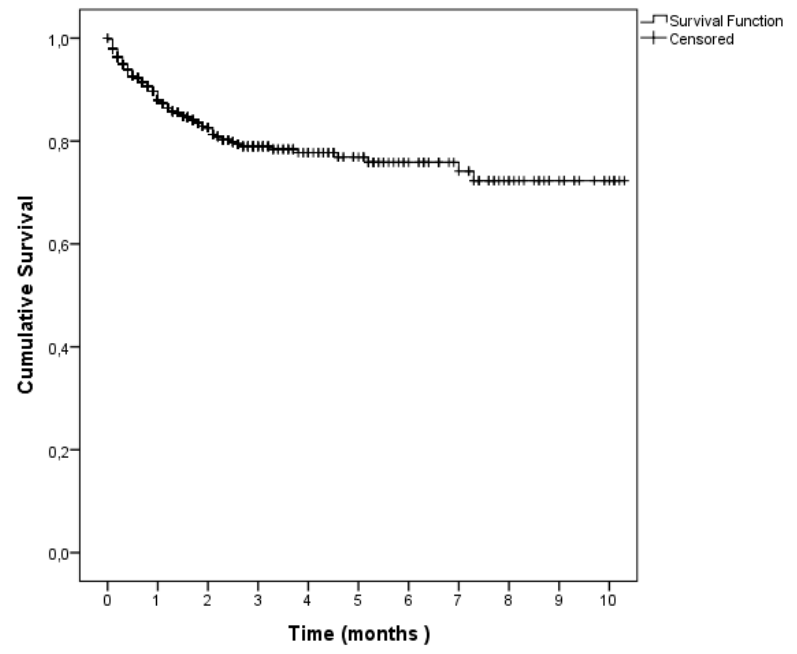

Figure 1. Time between Lung Cancer Diagnosis and Bone Metastases

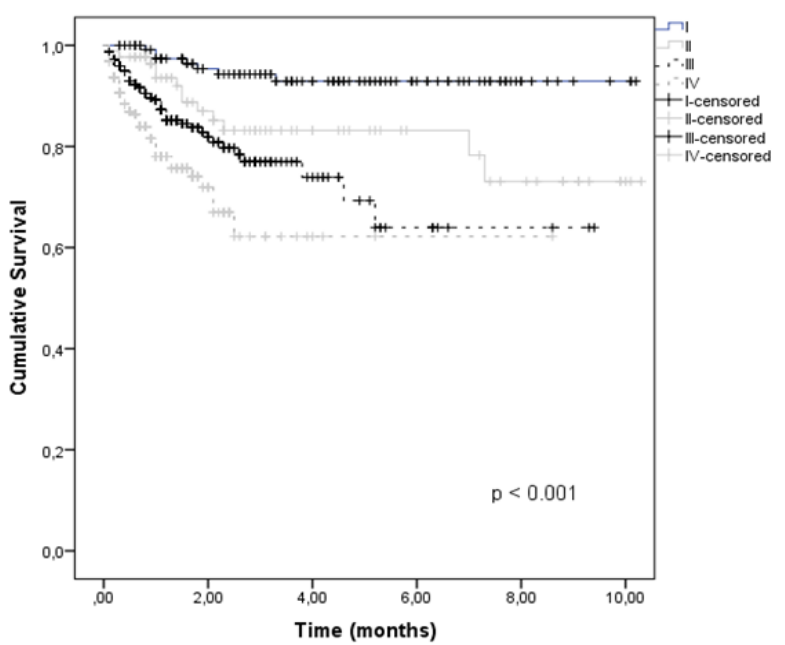

Figure 2. Time between Lung Cancer Diagnosis and Bone Metastases by Staging

are presented in Table 3 .

After adjusted for potential confounding, multivariate analysis revealed that younger age (HR $0.97 ; 95 \% \mathrm{CI}$, $0.95-0.99 ; \mathrm{p}=0.002)$, adenocarcinoma (HR $1.51 ; 95 \% \mathrm{CI}$, $1.06-2.15 ; \mathrm{p}=0.021)$, and treatment with chemotherapy, RT or CRT (HR 3.73; 95\% CI, 2.30-6.05; p < 0.001) were associated with the occurrence of BM (Table 4).

\section{Discussion}

The epidemiological data from this cohort of 1,025 NSCLC patients treated at a single cancer centre are consistent with other reports (Sathiakumar et al. 2013; Oliveira et al., 2016). The majority of patients were male $(60.6 \%)$ and elderly $(62.0 \%)$ and the most common histological subtype was adenocarcinoma (51.4\%).

Previous studies have shown that BM is one of the most common extranodal metastatic sites in LC and this disorder has important consequences for patients (Oikawa et al., 2012; Riihimaki et al., 2014). We found that 13.2\% of our cohort of patients diagnosed with NSCLC between 
Table 3. Cox Regression Analysis for Bone Metastasis Incidence (Univariate Analysis)

\begin{tabular}{|c|c|c|c|c|}
\hline \multirow[t]{2}{*}{ Characteristics } & \multicolumn{2}{|c|}{$\mathrm{BM}$} & \multirow[t]{2}{*}{ HR (CI 95\%) } & \multirow[t]{2}{*}{ P Value } \\
\hline & Yes $(\mathrm{N}=136)$ & No $(\mathrm{N}=889)$ & & \\
\hline Age (years, mean \pm SD) & $60.4 \pm 9.1$ & $63.8 \pm 9.4$ & $0.97(0.95-0.98)$ & 0.001 \\
\hline \multicolumn{5}{|l|}{ Gender } \\
\hline Male & $77(56.6)$ & $559(62.9)$ & Reference & 0.667 \\
\hline Female & $59(43.4)$ & $330(37.1)$ & $1.07(0.76-1.51)$ & \\
\hline \multicolumn{5}{|l|}{ Ethnicity } \\
\hline Non-white & $36(27.1)$ & $291(33.2)$ & Reference & 0.266 \\
\hline White & $97(72.9)$ & $585(66.8)$ & $1.24(0.84-1.82)$ & \\
\hline \multicolumn{5}{|l|}{ Marital Status } \\
\hline Without partner & $14(10.4)$ & $95(11)$ & Reference & 0.906 \\
\hline With partner & $120(89.6)$ & $769(89)$ & $1.03(0.59-1.79)$ & \\
\hline \multicolumn{5}{|l|}{ Years of Education } \\
\hline$\leq 8$ years of study & $67(50.0)$ & $454(52.7)$ & Reference & 0.808 \\
\hline$>8$ years of study & $67(50.0)$ & $408(47.3)$ & $1.04(0.74-1.46)$ & \\
\hline \multicolumn{5}{|l|}{ Smoking } \\
\hline Smokers/former smokers & $115(85.2)$ & $772(89.7)$ & Reference & 0.336 \\
\hline Never smokers & $20(14.8)$ & $89(10.3)$ & $1.26(0.78-2.03)$ & \\
\hline \multicolumn{5}{|l|}{ Alcohol consumption } \\
\hline Yes & $73(59.3)$ & $478(61.5)$ & Reference & 0.745 \\
\hline No & $50(40.7)$ & $299(38.5)$ & $1.06(0.74-1.52)$ & \\
\hline \multicolumn{5}{|l|}{ Histology } \\
\hline Non-adenocarcinoma & $51(37.5)$ & $448(50.4)$ & Reference & 0.056 \\
\hline Adenocarcinoma & $85(62.5)$ & $441(49.6)$ & $1.40(0.99-1.98)$ & \\
\hline \multicolumn{5}{|l|}{ Staging } \\
\hline$<\mathrm{IIIb}$ & $42(32.1)$ & $343(41.4)$ & Reference & $<0.001$ \\
\hline IIIb and IV & $89(67.9)$ & $486(58.6)$ & $2.62(1.78-3.85)$ & \\
\hline \multicolumn{5}{|l|}{ Body Mass Index } \\
\hline Underweight or normal weight & $75(64.1)$ & $524(70.5)$ & Reference & 0.768 \\
\hline Overweight or obese & $42(35.9)$ & $219(29.5)$ & $1.05(0.72-1.54)$ & \\
\hline \multicolumn{5}{|l|}{ Performance Status } \\
\hline $0-1$ & $113(83.1)$ & $637(73)$ & Reference & 0.865 \\
\hline$\geq 2$ & $23(16.9)$ & $236(27)$ & $1.04(0.65-1.64)$ & \\
\hline \multicolumn{5}{|l|}{ History of EGFR-TKI therapy } \\
\hline No & $126(92.6)$ & $865(97.3)$ & Reference & 0.052 \\
\hline Yes & $10(7.4)$ & $24(2.7)$ & $1.89(0.99-3.61)$ & \\
\hline \multicolumn{5}{|l|}{ NSCLC Treatment } \\
\hline $\mathrm{S}$ or $\mathrm{SC}$ & $23(16.9)$ & $212(23.8)$ & Reference & $<0.001$ \\
\hline $\mathrm{C}$ or RT or CRT & $113(83.1)$ & $677(76.2)$ & $3.46(2.13-5.60)$ & \\
\hline
\end{tabular}

HR, Hazard Ratio; CI, Confidence Interval; BM, Bone Metastasis; EGFR-TKI, Epidermal Growth Factor Receptor-tyrosine Kinase Inhibitor; NSCLC, Non-Small-Cell Lung Cancer; C, Chemotherapy; RT, Radiotherapy; S, Surgery; SC, Surgery combined with chemotherapy; CRT, Chemotherapy combined with radiotherapy; The statistically significant values are highlighted in bold.

Table 4. Cox Regression Analysis for Bone Metastasis Incidence (Multivariate Analysis)

\begin{tabular}{llcc}
\hline & HR & $95 \%$ CI & P Value \\
\hline Age at Diagnosis (continuous variable) & 0.97 & $0.95-0.99$ & 0.002 \\
Histology: Adeno vs. Non-adeno & 1.51 & $1.06-2.15$ & 0.021 \\
Treatment: C or RT or CRT vs. S or SC* & 3.73 & $2.30-6.05$ & $<0.001$ \\
\hline
\end{tabular}

HR, Hazard Ratio; CI, Confidence Interval; Adeno, Adenocarcinoma; Non-adeno, Non-adenocarcinoma; NSCLC, Non-Small-Cell Lung Cancer; C, Chemotherapy; RT, Radiotherapy; S, Surgery; SC, Surgery combined with chemotherapy; CRT, Chemotherapy combined with radiotherapy 
January 2006 and December 2014 had developed BM in the course of the disease. A prospective study of 274 patients with LC reported a similar result: $12.4 \%$ incidence of BM during follow-up (Katakami et al., 2014). However, these results disagree with findings from others studies in which BM frequency varied between $19.8 \%$ and $34.0 \%$ (Santini et al., 2015; Sathiakumar et al., 2013; Mu Sun et al., 2011). The divergence in the reported frequency of $\mathrm{BM}$ in patients with LC may be due to methodological differences between the studies, particularly with respect to the follow up of patients and clinical investigation of BM. It should be noted that patients who had BM at the time of their LC diagnosis were excluded from our study population.

The interval between being diagnosed with LC and developing BM typically ranges from 6 to 23 months (Santini et al., 2015; Hendriks et al., 2014; Katakami et al., 2014; Decroisette et al., 2011), which is consistent with our results. In this study, the mean interval between NSCLC diagnosis and BM development was 8.07 months. Santini et al., (2015) reported that the median interval between diagnosis of NSCLC and development of BM was 19 months for patients diagnosed at stage I, 21 months for patients diagnosed at stage II, 12 months at stage IIIa and 10 months for patients at stage IIIb. Decroisette et al., (2011) reported that the mean interval between LC diagnosis and diagnosis of BM was 192 days (6.3 months).

The present study evaluated how socio-demographic and clinical variables affected the probability of development BM in patients with NSCLC. Multivariate analysis showed that age at diagnosis, histological subtype and NSCLC treatment were associated with probability of developing BM. Previous studies based on review of medical charts (Oliveira et al., 2016), and population-based data (Riihimaki et al., 2014; Cetin et al., 2014) have reported similar results for this population. A study based on data from the Danish National Patient Registry for the period 1999 to 2010 showed that $50.3 \%$ of 2,032 patients with BM had adenocarcinoma (Cetin et al., 2014). Another large study that investigated associations between clinical variables and occurrence of metastasis in 17,431 LC patients also found that patients with adenocarcinoma were more likely to develop BM (Riihimaki et al., 2014). Oliveira et al., (2016) evaluated the association between histological subtype and the occurrence of BM and found that BM were more frequent in patients with adenocarcinoma and were less frequent in patients with squamous cell carcinoma. In this analysis, patients with adenocarcinoma showed more risk for developing BM when were compared with patients with other histological subtypes $(\mathrm{HR}=1.5195 \% \mathrm{CI}, 1.06-2.15$; $\mathrm{p}=0.021)$.

In our data set youth was positively associated with risk of developing BM; a 1-year increase in age was associated with a $3 \%$ reduction in BM risk (HR 0.97; 95\% CI, 0.95-0.99; $\mathrm{p}=0.002)$. This result contrasts with another published study of advanced NSCLC cases (Katakami et al. 2014), but is consistent with two other previous studies (Riihimaki et al., 2014; Harries et al., 2014). A population-based study that included LC patients demonstrated that BM was more common amongst younger patients (Riihimaki et al., 2014) and multivariate analysis of a large cohort (7064 breast cancer patients) produced similar results: the HR for risk of developing $\mathrm{BM}$ was higher in younger breast cancer patients (Harries et al., 2014). Age-related differences in survival are well-documented (Arnold et al., 2016; Riihimaki et al., 2014; Subramanian et al., 2010). According to Riihimaki et al., (2014) younger patients with LC has a better prognosis and this increases the time at risk for developing metastasis.

In NSCLC patients, treatment is determined by stage at diagnosis. In the early stages treatment may be curative and resection of NSCLC remains the standard treatment; however the majority of NSCLC patients present in the advanced stages and this difficult the management of the disease. In more advanced disease it is common to use an intensive treatment regimen comprising palliative chemotherapy or RT and a proportion of patients diagnosed in the advanced stages do not receive any systemic anti-neoplastic treatment (Urvay et al., 2016; Araújo et al., 2014; Pitz et al., 2009). Survival is higher in NSCLC patients who undergo surgical resection than in patients treated with CRT (Dickhoff et al., 2016). In the current study, patients who were initially treated with chemotherapy, RT or CRT were more likely to develop BM: in the multivariate analysis, the HR for developing BM was 3.73 (95\% CI, 2.30-6.05; $\mathrm{p}<0.001)$ in comparison with patients initially treated with surgery or SC. Authors reported that the timing of the first peak in development of metastasis occurs at 7 to 9 months after surgery in patients with early-stage (I-IIIA) NSCLC (Kelsey et al., 2013; Demicheli et al., 2012). On the other hand, in the present study, staging was a predictor of BM development only in the univariate analysis. Although there are stage-specific treatment guidelines for NSCLC (Detterbeck et al., 2013), other factors such as comorbidities, performance status, pulmonary function tests results and patient preferences may influence treatment decisions (Nadpara et al., 2015; Cetin et al., 2014; De Rijke et al., 2004).

In this study, EGFR-TKI treatment was not a predictor of BM development, which is in line with earlier reports (Katakami et al., 2014; Hendriks et al., 2014). A prospective multicenter cohort study that used multiple regression to evaluate $\mathrm{BM}$ predictors found that stage IV, PS 1 or greater at enrolment, and high serum bone alkaline phosphatase at baseline were positively associated with development of BM, whereas EGFR-TKI treatment was not a predictor (Katakami et al., 2014). A retrospective case-control study indicated that the mean interval between NSCLC and development of BM was longer for EGFR+ patients first line treated with EGFR-TKI compared to those treated initially with chemotherapy, however there was no statistically significant difference between these groups (Hendriks et al., 2014). Our findings relating to EGFR-TKI must be treated with caution because of the small number of patients in this group. It is important to note that we evaluated associations between development of BM and demographic and clinical variables whereas others researchers have analysed blood chemistry and bone turnover markers as predictors of BM risk (Zhou et al., 2012; Katakami et al., 2014).

Asian Pacific Journal of Cancer Prevention, Vol 20 
In conclusion, this study indicates that younger age, histological subtype adenocarcinoma and treatment with chemotherapy, RT or CRT are independent predictors of $\mathrm{BM}$ development. There is a dearth of research on this topic and further investigations are needed to improve our understanding of how patient variables influence the development of BM in NSCLC.

\section{Source of support}

None.

\section{Disclosure}

The authors report no conflicts of interest.

\section{Acknowledgements}

The authors declare no acknowledgements.

\section{References}

Araujo LH, Baldotto CS, Zukin M, et al (2014) Survival and prognostic factors in patients with non-small cell lung cancer treated in private health care. Rev Bras Epidemiol, 174, 10001-4.

Arnold BN, Thomas DC, Rosen JE, et al (2016) Lung cancer in the very young: Treatment and survival in the national cancer data base. $J$ Thorac Oncol, 11, 1121-31.

Bae HM, Lee SH, Kim TM, et al (2012). Prognostic factors for non-small cell lung cancer with bone metastasis at the time diagnosis. Lung Cancer, 77, 572-7.

Brasil. Instituto Nacional de Câncer (2018). Estimativa 2018: Incidência de Câncer no Brasil. http://www.inca.gov.br/. Accessed 27 july 2018.

Cetin K, Christiansen CF, Jacobsen JB, Norgaard M, Sorensen HT (2014). Bone metastasis, skeletal-related events, and mortality in lung cancer patients: a Danish population-based cohort study. Lung Cancer, 86, 247-54.

Coleman RE (2006). Clinical features of metastatic bone disease. Clin Cancer Res, 15, 6243-9.

Da Silva GT, Bergmann A, Thuler LC (2016). Skeletal related events in patients with bone metastasis arising from nonsmall cell lung cancer. Support Care Cancer, 24, 731-6.

De Rijke JM, Schouten LJ, Velde GPMt, et al (2004). Influence of age, comorbidity and performance status on the choice of treatment for patients with non-small cell lung cancer; results of a population-based study. Lung Cancer, 46, 233-45.

Decroisette C, Monnet I, Berard H, et al (2011). Epidemiology and treatment costs of bone metastases from lung cancer: a French prospective, observational, multicenter study. J Thorac Oncol, 6, 573-82.

Demicheli R, Fornili M, Ambrogi F, et al (2012). Recurrence dynamics for non-small-cell lung cancer: effect of surgery on the development of metastases. J Thorac Oncol, 7, 723-30.

Detterbeck FC, Lewis SZ, Diekemper R, et al (2013). Executive summary: diagnosis and management of lung cancer, 3rd ed: American College of Chest Physicians evidence-based clinical practice guidelines. Chest, 143, 7-37.

Dickhoff C, Dahele M, de Langen AJ, et al (2016). Population-based patterns of surgical care for stage IIIA NSCLC in Netherlands between 2010-2013. J Thorac Oncol, 11, 566-72.

Duran I, Fink MG, Bahl A, et al (2017). Health resource utilisation associated with skeletal-related events in patients with bone metastases secondary to solid tumours: regional comparisons in an observational study. Eur J Cancer Care,
26, e12452.

Ezat SW, Syed SM, Noraziani K, et al (2013). Skeletal-related events among breast and prostate cancer patients: towards new treatment initiation in malasia's hospital setting. Asian Pac J Cancer Prev, 14, 3357-62.

Harries M, Taylor A, Holmberg L, et al (2014). Incidence of bone metastases and survival after a diagnosis of bone metastases in breast cancer patients. Cancer Epidemiol, 38, 427-34.

Hendriks LE, Smit EF, Vosse BA, et al. (2014). EGFR mutaded non-small cell lung cancer patients: more prone to development of bone and brain metastases?. Lung Cancer, 84, 86-91.

Hirsh V (2009). Skeletal disease contributes substantially to morbidity and mortality in patients with lung cancer. Clin Lung Cancer, 10, 223-9.

Hoefeler H, Duran I, Hechmati G, et al (2014). Health resource utilization associated with skeletal-related events in patients with bone metastases: Results from a multinational retrospective - prospective observational study - a cohort from 4 European countries. J Bone Oncol, 3, 40-8.

Katakami N, Kunikane H, Takeda K, et al (2014). Prospective study on the incidence of bone metastasis (BM) and skeletal-related events (SREs) in patients with stage IIIB and IV lung cancer-CSP-HOR 13. J Thorac Oncol, 9, 231-8.

Kelsey CR, Fornili M, Ambrogi F, et al (2013). Metastasis dynamics for non-small-cell lung cancer: effect of patient and tumor-related factors. Clin Lung Cancer, 14, 425-32.

Kuchuk M, Kuchuk I, Sabri E, et al (2015). The incidence and clinical impact of bone metastases in non-small cell lung cancer. Lung Cancer, 89, 197-202.

Lipton A, Fizazi K, Stopeck AT, et al (2016). Effect of denosumab versus zoledronic acid in preventing skeletal-related events in patients with bone metastases by baseline characteristics. Eur J Cancer, 53, 75-83.

Mu Sun J, Ahn JS, Lee S, et al (2011). Predictors of skeletal-related events in non-small cell lung cancer patients with bone metastases. Lung Cancer, 71, 89-93.

Nadpara PA, Madhavan SS, Tworek C, et al (2015). Guideline-concordant lung cancer care and associated health outcomes among elderly patients in the Unites States. $J$ Geriatr Oncol, 6, 101-10.

Oikawa A, Takahashi H, Ishikawa H, et al (2012). Appication of conditional probability analysis to distant metastases from lung cancer. Oncol Lett, 3, 629-34.

Oliveira MB, Mello FC, Paschoal ME (2016). The relationship between lung cancer histology and the clinicopathological characteristics of bone metastases. Lung Cancer, 96, 19-24.

Oster G, Lamerato L, Glass AG, et al (2013). Natural history of skeletal-related events in patients with breast, lung, or prostate cancer and metastases to bone: a 15-year study in two large US health systems. Support Care Cancer, 21, 3279-86.

Pereira J, Body JJ, Gunther O, et al (2016). Cost of skeletal complications from bone metastases in six European countries. J Med Econ, 19, 611-8.

Phanphaisarn A, Patumanond J, Settakorn J, et al (2016). Prevalence and survival patterns of patients with bone metastasis from common cancers in Thailand. Asian Pac J Cancer Prev, 17, 4335-40.

Pitz MW, Musto G, Demers AA, et al (2009). Survival and treatment pattern of non-small lung cancer over 20 years. $J$ Thorac Oncol, 4, 492-8.

Riihimäki M, Hemminki A, Fallah M, et al (2014). Metastatic sites and survival in lung cancer. Lung Cancer, 86, 78-84.

Roodman GD (2004). Mechanisms of bone metastasis. N Engl $J$ Med, 350, 1655-64.

Santini D, Barni S, Intagliata S, et al (2015). Natural history of 
non-small-cell lung cancer with bone metastases. Sci Rep, 5, 18670.

Sathiakumar N, Delzell E, Morrisey MA, et al (2013). Mortality following bone metastasis and skeletal-related events among patients 65 years and above with lung cancer: A population-based analysis of U.S Medicare beneficiaries, 1999-2006. Lung India, 30, 20-6.

Subramanian J, Morgensztern D, Goodgame B, et al (2010). Distinctive characteristics of non-small cell lung cancer (NSCLC) in the young: a Surveillance, Epidemiology, and End Results (SEER) analysis. J Thorac Oncol, 5, 23-8.

Torre LA, Bray F, Siegel RL, et al (2015). Global cancer statistics, 2012. CA Cancer J Clin, 65, 87-108.

Tsuya A, Kurata T, Tamura K, Fukuoka M (2007). Skeletal metastases in non-small cell lung cancer: A retrospective study. Lung Cancer, 57, 229-32.

Ulas A, Bilici A, Durnali A, et al (2016). Risk factor for skeletal-related events (SREs) and factors affecting SRE-free survival for nonsmall cell lung cancer patients with bone metastases. Tumour Biol, 7, 1131-40.

Urvay SE, Yucel B, Erdis E, et al (2016). Prognostic factors in stage III Non-small cell lung cancer patients. Asian Pac J Cancer Prev, 17, 4693-7.

Zhou Z, Chen ZW, Yang XH, et al (2012). Establishment of a biomarker model for predicting bone metastasis in resected stage III non-small cell lung cancer. J Exp Clin Cancer Res, 26, 31-4.

\section{c) (7) (8)}

This work is licensed under a Creative Commons AttributionNon Commercial 4.0 International License. 